\title{
CaHSP18.1a, a Small Heat Shock Protein from Pepper (Capsicum annuum L.), Positively Responds to Heat, Drought, and Salt Tolerance
}

\author{
Yan-Li Liu ${ }^{1,+}$, Shuai Liu ${ }^{1,+}$, Jing-Jing Xiao ${ }^{1}$, Guo-Xin Cheng ${ }^{1}$, Haq Saeed ul $^{1,2}$ and Zhen-Hui Gong ${ }^{1, * *(1)}$ \\ 1 College of Horticulture, Northwest A\&F University, Yangling 712100, China; \\ 2018060114@nwafu.edu.cn (Y.-L.L.); liushuai5887@nwsuaf.edu.cn (S.L.); 2018050339@nwafu.edu.cn (J.-J.X.); \\ 2014060108@nwsuaf.edu.cn (G.-X.C.); Saeed_ulhaq@nwsuaf.edu.cn (H.S.u.) \\ 2 Department of Horticulture, University of Agriculture Peshawar, Peshawar 25120, Pakistan \\ * Correspondence: zhgong@nwsuaf.edu.cn; Tel.: +86-029-8708-2102; Fax: +86-029-8708-2613 \\ + Co-first author.
}

check for

updates

Citation: Liu, Y.-L.; Liu, S.; Xiao, J.-J.; Cheng, G.-X.; ul, H.S.; Gong, Z.-H. CaHSP18.1a, a Small Heat Shock Protein from Pepper (Capsicum annuum L.), Positively Responds to Heat, Drought, and Salt Tolerance. Horticulturae 2021, 7, 117. https:// doi.org/10.3390/horticulturae 7050117

Academic Editor: Yuyang Zhang

Received: 1 April 2021

Accepted: 11 May 2021

Published: 18 May 2021

Publisher's Note: MDPI stays neutral with regard to jurisdictional claims in published maps and institutional affiliations.

Copyright: (c) 2021 by the authors. Licensee MDPI, Basel, Switzerland. This article is an open access article distributed under the terms and conditions of the Creative Commons Attribution (CC BY) license (https:/ / creativecommons.org/licenses/by/ $4.0 /)$.

\begin{abstract}
Pepper is a thermophilic crop, shallow-rooted plant that is often severely affected by abiotic stresses such as heat, salt, and drought. The growth and development of pepper is seriously affected by adverse stresses, resulting in decreases in the yield and quality of pepper crops. Small heat shock proteins (s HSPs) play a crucial role in protecting plant cells against various stresses. A previous study in our laboratory showed that the expression level of CaHSP18.1a was highly induced by heat stress, but the function and mechanism of CaHSP18.1a responding to abiotic stresses is not clear. In this study, we first analyzed the expression of CaHSP18.1a in the thermo-sensitive B6 line and thermo-tolerant R9 line and demonstrated that the transcription of CaHSP18.1a was strongly induced by heat stress, salt, and drought stress in both R9 and B6, and that the response is more intense and earlier in the R9 line. In the R9 line, the silencing of CaHSP18.1a decreased resistance to heat, drought, and salt stresses. The silencing of CaHSP18.1a resulted in significant increases in relative electrolyte leakage (REL) and malonaldehyde (MDA) contents, while total chlorophyll content decreased under heat, salt, and drought stresses. Overexpression analyses of CaHSP18.1a in transgenic Arabidopsis further confirmed that CaHSP18.1a functions positively in resistance to heat, drought, and salt stresses. The transgenic Arabidopsis had higherchlorophyll content and activities of superoxide dismutase, catalase, and ascorbate peroxidase than the wild type (WT). However, the relative conductivity and MDA content were decreased in transgenic Arabidopsis compared to the wild type (WT). We further showed that the CaHSP18.1a protein is localized to the cell membrane. These results indicate CaHSP18.1a may act as a positive regulator of responses to abiotic stresses.
\end{abstract}

Keywords: CaHSP18.1a; gene silencing; transgenic Arabidopsis; heat stress; pepper; gene expression

\section{Introduction}

Plants can tolerate considerable biotic and abiotic stresses in their complex and changing environments, including drought, high salt, extreme temperatures, and oxidation $[1,2]$. To mitigate stresses, plants have developed several protective mechanisms. Heat shock proteins (HSPs) can maintain protein homeostasis and prevent or repair the misfolding of proteins in abiotic stresses response. Moreover, HSPs are evolutionarily conserved molecular chaperones widely found among various plant taxa [3-5]. Plant HSPs also play critical roles in the folding, transport, degradation, and assembly of proteins under normal and stress conditions [6]. In response to high temperatures, plant cells dramatically increase the concentrations of HSPs to prevent heat-related damage and increase plant thermotolerance [7]. In addition, HSPs are also involved in plant growth and development under normal conditions, including the growth of flowers and seeds as well as fruit set, development [8], tuberization [9], and nutrient uptake [10]. HSPs are present in the cell membrane 
and cytoplasm, nucleus, and cell organelles such as the mitochondria, chloroplasts, and endoplasmic reticulum [11,12].

HSPs, based on their sequence homology and molecular weight, are generally grouped into the following different families: HSP20s, HSP60s, HSP70s, HSP90s, and HSP100s [13,14]. Of the five conserved families, HSP20s, are also called small heat shock proteins (s HSPs). The molecular weights of HSP20s range between 15 and $42 \mathrm{kDa}[13,15,16]$. Furthermore, one of the distinctive characteristics of HSP20s is their ability to bind to substrate proteins without ATP, and they also have a strong ability to bind to denatured substrates [15-18]. Thus, s HSPs are highly able to maintain the stability of foreign proteins in cells to prevent them from aggregating. Although there are many types of substrate proteins, s HSPs have a flexible $\mathrm{N}$-terminus and $\alpha$-crystallin domain (ACD) hydrophobic surface that can adapt to bind these different protein substrates. In addition, s HSPs can be combined with different substrates in different ways, which makes s HSPs able to bind to a wider variety of proteins and to provide more complicated mechanisms of action among HSPs [19].

Korotaeva et al. [20] and Nieto-Sotelo et al. [21] showed that different HSPs are differentially expressed in different species, and even among different genotypes of the same species. It has been reported that the overexpression of AtHSP17. 6A increased the penetration resistance of Arabidopsis [22]. AtHSP21 improved the heat resistance of transgenic Arabidopsis and extended the memory time of plants subjected to heat resistance, such that Arabidopsis was more heat resistant when subjected to heat stress again [23]. Some studies have also reported that HSP gene expression positively regulated protective enzyme activities. For example, in Arabidopsis, overexpression of AtHSP17.8 enhanced SOD activity [24]. Similarly, overexpression of HSP16.9 in tobacco increased the activities of POD, CAT, and SOD [25].

Pepper (Capsicum annuum L.) is one of the most important economical and medicinal vegetable crops worldwide [26].Pepper is usually cultivated in warm regions under temperatures of $15-34{ }^{\circ} \mathrm{C}$ [27]. Salt, drought, and heat stress can limit pepper growth and development and severely damage pepper pollination and seed set, which can lead to flower and fruit abscission and thus lower pepper fruit yield and quality [28,29].HSP20s in pepper play a major role in environmental stress responses, and a total of 35 pepper HSP20s were identified by Guo et al. [30]. All HSP20s were named based on their molecular weights, and stress-related cis-elements were detected in the promoter regions, including heat shock elements (HSEs), TATA boxes, CCAAT motifs, and TC-rich repeats [26]. Many CaHSP20 genes are not expressed across different pepper tissues (i.e., root, stem, leaf, and flower tissues). In recent years, the functions of CaHSP22.4, CaHSP25.9, CaHSP16.4, CaHSP24.2, and CaHSP26 have been identified. CaHSP16.4 is localized to the cytoplasm and nucleus, while in Arabidopsis lines with CaHSP16.4 overexpression, increased tolerance to heat stress has been observed [31]. Guo et al. [26] also found that overexpression of CaHSP22.4, which is located in the mitochondria and cytoplasm, increased heat tolerance in Arabidopsis, with the expression increasing when pepper plants were subjected to high temperature. Similarly, the CaHSP25.9 protein was localized to the cell membrane and cytoplasm, and positively regulates heat, salt, and drought stress tolerance in pepper (Capsicum annuum L.) [32]. Pepper CaHSP24.2 is localized to mitochondria, the cytoplasm, and chloroplasts, where CaHSP24.2 enhances the thermo-tolerance of transgenic Arabidopsis plants and regulates the expression of heat stress-related genes [30]. He et al. [33] overexpressed CaHSP26, which enhanced the tolerance of heat stress in Arabidopsis. Interestingly, heat-tolerance and salt-tolerance decreased in CaHSP22.0-silenced pepper [34]. All these studies suggest that sHSP20s may participate in responses to heat stress [35] and contribute to the acquisition of pepper thermo-tolerance [30].

Among the 35 CaHSP20s examined, the expression level of CaHSP18.1a was increased in both the B6 and R9 lines under heat stress [30]. Moreover, sequence analysis showed that CaHSP18.1a contained an HSE, and some other stress-related elements were also identified [30]. Based on the above findings, we analyzed the subcellular localization and expression pattern of CaHSP18.1a in different pepper tissues, as well as its response to salt, 
drought, and heat stresses. Virus-induced gene silencing (VIGS) was preliminarily used to analyze the functions of CaHSP8.1a in response to stress in pepper plants. In addition, overexpression (OE) in transgenic Arabidopsis thaliana indicated that CaHSP18.1a plays a positive regulatory role in the responses to heat, salt, and drought stress. Our results provide a basis for further functional studies of CaHSP18.1a in other important crop species and in its role in stress tolerance.

\section{Materials and Methods}

\subsection{Plant Materials and Growth Conditions}

The thermo-tolerant pepper line R9 (a sweet pepper from the World/Asia Vegetable Research and Development Center, PP0042-51) and the thermo-sensitive pepper line B6 (selected by the Pepper Research Group, College of Horticulture, Northwest A\&F University, Yangling, China) were used in this study. Pepper seedlings were cultivated in a growth chamber under the following growth conditions prior to various treatments: daily $16 \mathrm{~h}$ light $/ 8 \mathrm{~h}$ dark cycles and $65 \%$ relative humidity until the 6-8 true leaves stage. The temperature was changed throughout the course of the experiment. R9 peppers were grown under $25 / 20^{\circ} \mathrm{C}$ day /night temperatures to enable analyzing gene expression $[30,36,37]$. However, the growing conditions for use of virus-induced gene silencing (VIGS) in the R9 pepper line were $22 / 18{ }^{\circ} \mathrm{C}$ day/night temperatures [38]. Arabidopsis ecotype Col-0 variety seedlings were incubated at $65 \%$ relative humidity, $22 / 18^{\circ} \mathrm{C}$ (day/night), and $16 \mathrm{~h} / 8 \mathrm{~h}$ (light/dark) photoperiod conditions [37,38].

\subsection{RNA Extraction and Real-Time Fluorescent Quantitative PCR qRT-PCR Analysis}

Total RNA was extracted using the Trizol method [28]. Synthesis of cDNA was conducted with the PrimeScript ${ }^{\mathrm{TM}}$ kit (Takara, Dalian, China) according to the manufacturer's instructions. First, we downloaded the amino acid sequence of CaHSP18.1 $a$ from the Pepper Genomics Database (accessed date on 1 January 2020, http:/ / peppergenome.snu.ac.kr/: Accession number: CA08g17060). Primer Premier 5.0 was used to design primers, and primer specificity was detected using NCBI Primer BLAST (https:/ /www.ncbi.nlm.nih. gov/tools / primer-blast/, accessed on 5 January 2020) (Supplementary Table S1). The pepper ubiquitin binding gene CaUbi3 (Accession number AY486137) was used as a reference gene [39]. qRT-PCR was performed using the iQ5.0 Bio-Rad iCycler thermal cycler (BioRad, Hercules, CA, USA). The SYBR Green Super mix (Takara, Dalian, China) was used in the qRT-PCR reaction system following the manufacturer's instructions. The relative expression levels of the gene were analyzed using the $2^{-\Delta \Delta C T}$ method [40].

\subsection{Subcellular Localization of CaHSP18.1a Protein}

The ORF (open reading frame) of CaHSP18.1 $a$ without a termination codon was PCRamplified using a specific primer pair (Supplementary Table S1). The resulting CaHSP18.1a fragment was cloned into the pVBG2307: GFP vector with $\mathrm{XbaI}$ and $\mathrm{KpnI}$ restriction sites. The pVBG2307:CaHSP18.1a: GFP fusion protein transient expression vector and the control vector pVBG2307: GFP, after having been successfully constructed, were transformed into Agrobacterium tumefaciens strain GV3101, which was then injected into tobacco (Nicotiana tabacum) leaves to induce transient expression. After dark cultivation for approximately 36 $h$, epidermis samples of tobacco leaves were photographed under a fully automatic upright fluorescence microscope on the public platform of the College of Horticulture, Northwest A\&F University, and the fluorescence patterns in the cells were observed; we specifically used the method described by Yu et al. [41].

\subsection{Virus-Induced Gene Silencing of CaHSP18.1a}

A 256-bp fragment of the CaHSP18.1a ORF was PCR-amplified using a specific primer pair (Supplementary Table S1). The underlined sequences are restriction enzyme cleavage sites (for XbaI and KpnI). The resulting CaHSP18.1 $a$ fragment was inserted into TRV2:00 vectors, with the empty vector TRV2:00 and TRV2: CaPDS (phytoene desaturase gene) used 
as negative and positive controls. When $\mathrm{R} 9$ plants reached the two true leaves stage, we followed the method of Wang et al [38], which involved mixing the pTRV1 bacterial culture with an equal volume of the TRV2:00, TRV2: CaPDS, and TRV2: CaHSP18.1 a cultures; this solution was injected into the leaves of R9 plants. After incubation in the dark at $18{ }^{\circ} \mathrm{C}$ for 2 days, plants were transferred to incubators under preset normal conditions. After 35 days, when most of the leaves of the TRV2-CaPDS pepper plants had become bleached, total RNA was extracted from the leaves of the silenced TRV2: CaHSP18.1a plants and the negative control TRV2:00 plants, and qRT-PCR was used to detect the CaHSP18.1a expression level, which was used to calculate silencing efficiency.

\subsection{Generation of CaHSP18.1a-Overexpression Arabidopsis Lines}

The entire coding regions of CaHSP18.1 $a$ were cloned into the pVBG2307 vector between the XbaI and KpnI restriction sites to yield the final plasmid pVBG2307: CaHSP18.1a used for genetic transformation (the primers used for this experiment are given in Supplementary Table S1). The recombinant fusion vector was transformed into Agrobacterium strain GV3101 and transformed into Arabidopsis thaliana as described by Clough and Bent [42]. Transformed strains of pVBG2307 expression vector were screened with kanamycin and confirmed by PCR verification. We extracted DNA to detect the correctness of the target band. First, the fragment lengths of the bands were compared with the target band, obtaining, respectively, the OE1, OE2, OE3, OE4, and OE5 lines. Next, we performed real-time qRT-PCR quantitative analysis and detected the transcript from the inserted construct (Supplementary Figure S2B). CaHSP18.1 $a$ was thus determined to be expressed in large quantities in the OE3, OE2, and OE1 strains, but the wild-type gene was not detected. Both the target band and qRT-PCR results indicated that the CaHSP18.1a gene was successfully transferred into Arabidopsis thaliana, and the obtained T3-generation Arabidopsis thaliana could thus be used for further experiments.

\subsection{Experimental Treatments and Sample Collection}

The roots, stems, and leaves of R9 and B6 pepper seedlings (at the 4-to-6-leaf stage) grown under normal conditions were sampled in order to analyze expression of CaHSP18.1a in different tissues. For the thermotolerance treatment, R9 and B6 pepper seedlings (again, at the 4-to-6-leaf stage) were grown at $42{ }^{\circ} \mathrm{C}$ for $24 \mathrm{~h}$, and root, stem, and leaf samples were collected from stress-treated seedlings at $0,0.5,1,3$, and $6 \mathrm{~h}$ post-treatment. For the drought stress treatment, the roots of R9 seedlings were soaked in $300 \mathrm{mM}$ mannitol, and root, stem, and leaf samples were collected from stress-treated seedlings at $0,3,6,12$, and $24 \mathrm{~h}$ after treatment.

To analyze the function of CaHSP18.1 $a$ in response to pepper abiotic stress, silenced pepper seedlings and TRV2:00 pepper seedlings were grown at $42{ }^{\circ} \mathrm{C}$ for $24 \mathrm{~h}$. For the drought and salt stresses, seedlings were treated with $300 \mathrm{mM}$ mannitol and $300 \mathrm{mM} \mathrm{NaCl}$ for $24 \mathrm{~h}$. Samples were collected and malondialdehyde (MDA) content, total chlorophyll content, and relative electrolyte leakage (REL) were determined. To identify the tolerance of CaHSP18.1a-overexpression in Arabidopsis thaliana in response to heat, salt, and drought stress, T3-generation Arabidopsis thaliana and wild-type lines were treated as described.

For heat stress, 2-week-old OE3 seedlings were treated at $42{ }^{\circ} \mathrm{C}$ for $24 \mathrm{~h}$. For drought stress, water was withheld from 3-week-old transgenic Arabidopsis seedlings for $10 \mathrm{~d}$. Samples were collected to measure the total chlorophyll contents, MDA content, REL, the activity levels of CAT, SOD, and ascorbic acid peroxidase (APX). For salt stress, the seeds of WT and transgenic lines were sown on MS medium with 0,100 , and $150 \mathrm{mM} \mathrm{NaCl}$, and the roots lengths were measured after 10 days of treatment. The germination rate was determined after $6 \mathrm{~d}$. The 3-week-old WT and transgenic plants were irrigated with $200 \mathrm{mM} \mathrm{NaCl}$ solution for 7 days, once every 2 days. 


\subsection{Measurement of Physiological Indicators}

REL was estimated using the thiobarbituric acid reaction [43]. Total chlorophyll content was determined in the leaves according to methods previously described by Arkus et al [44]. Lipid peroxidation was determined by measuring the MDA content following the method of Campos et al [45]. POD and SOD activity levels were measured following the methods of Guo et al [46]. APX activity was measured using the methods of Nakano and Asada [47]. CAT activity was determined following AebiH [48].

\subsection{Statistical Analyses}

The experimental data were analyzed using Origin (Origin Lab, Northampton, MA, USA) and SPPS (SPSS Inc., Chicago, IL, USA). Significance tests for differences between control and stress treatments were assessed at a $p \leq 0.05$ level of significance. All experiments were performed and analyzed separately based on three biological replicates.

\section{Results}

3.1. Expression of the CaHSP18.1a in Pepper Plants under Abiotic Stress

To confirm whether heat, drought, and salt have an effect on the expression of CaHSP18.1a, R9 and B6 pepper lines were used to analyze the expression of CaHSP18.1a under heat, drought, and salt stress. Under heat stress (Figure 1A,B), the expression levels of CaHSP18.1a were significantly upregulated (samples IV, V, and VI) at $3 \mathrm{~h}$ in the roots, stems, and leaves of R9 plants and peaked at $6 \mathrm{~h}$ (sample Point V) in B6 plants. However, during the $22{ }^{\circ} \mathrm{C}$ recovery stage, the recovery times of CaHSP18.1a in the R9 and B6 strains differed. In roots, the expression levels of CaHSP18.1a in R9 and B6 plants returned to baseline after a $6 \mathrm{~h}$ recovery at the normal temperature (sample VII point) (Figure 1B). In stems, the expression level of CaHSP18.1 a returned to a normal level after $3 \mathrm{~h}$ under the $22{ }^{\circ} \mathrm{C}$ recovery conditions for both the $\mathrm{R} 9$ and $\mathrm{B} 6$ plants (point VI in samples) (Figure 1C). In leaves, the expression level of CaHSP18.1a returned to normal levels at $24 \mathrm{~h}$ (sample VIII point) (Figure 1D). We also analyzed the expression pattern of CaHSP18.1 $a$ under salt and drought stresses (Figure 1E-H). After 6-h NaCl treatments at different concentrations, the expression of CaHSP18.1a in R9 and B6 leaves and roots was highest under the $150 \mathrm{mM}$ $\mathrm{NaCl}, 100 \mathrm{mM} \mathrm{NaCl}$ treatments, respectively. The transcription of CaHSP18.1a was higher in $\mathrm{R} 9$ under different concentrations of $\mathrm{NaCl}$ treatment (Figure 1E, F). After 6-h treatments with different concentrations of mannitol, the expression of CaHSP18.1 $a$ in R9 and B6 leaves was the highest after the $150 \mathrm{mM}$ mannitol treatment; the highest expression of CaHSP18.1a was observed in R9 and B6 roots subjected to the 50mM mannitol treatment (Figure 1G, H). In addition, the transcription of CaHSP18.1 $a$ was higher in R9 under different concentrations of mannitol. This analysis showed that the expression of CaHSP18.1a in pepper was induced by heat, salt, and drought. The response times of CaHSP18.1 $a$ in different organs of different pepper lines differed, and the response was more intense and more early in the R9 line, which suggests that CaHSP18.1a plays a substantial role in plant responses to heat stress. 

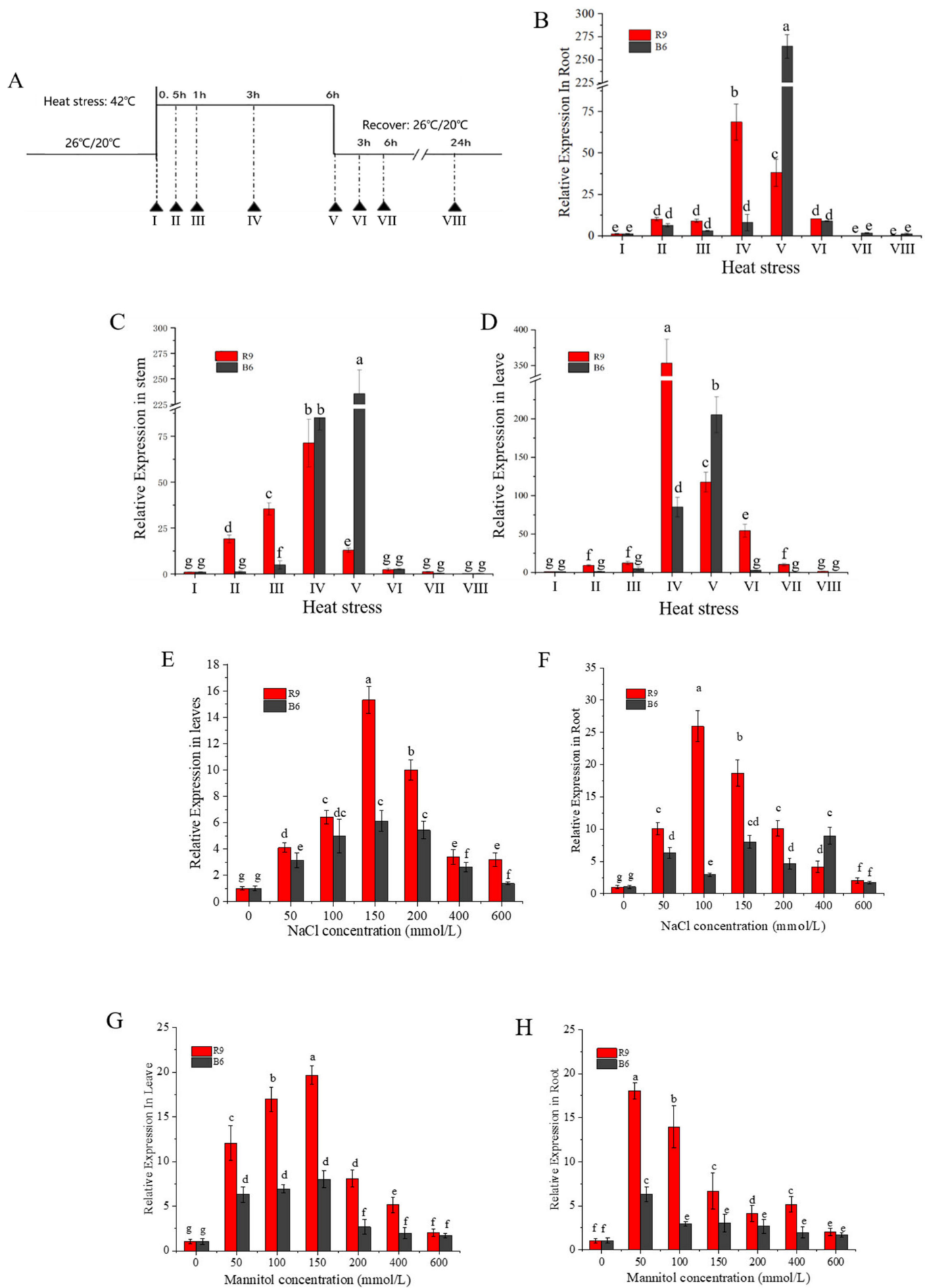

Figure 1. The expression characteristics of CaHSP18.1 $a$ in peppers in response to heat stress. (A) Time course of heat stress treatment and normal temperature recovery; the sampling time points are represented by triangles (pepper sample points I-VIII); (B-D) The expression levels of CaHSP18.1 $a$ in roots, stems, and leaves of R9 and B6 plants at each sampling time point; the expression levels of B6 and R9 plants were based on the reference level of their samples, and CaUBI-3 was selected as the reference gene.(E-H) The expression levels of CaHSP18.1a following salt and drought treatment in R9 and B6 leaves and roots. The data presented are means with standard deviations of three biological replicates. Different letters denote statistical significance $(p \leq 0.05)$. 


\subsection{Subcellular Localization of CaHSP18.1a Protein}

To explore the subcellular localization of CaHSP18.1a, we constructed the pVBG2307: CaHSP18.1a: GFP fusion expression vector. Both pVBG2307: GFP and pVBG2307:CaHSP 18.1a: GFP fusion plasmids were introduced into Nicotiana tabacum leaves, and fluorescence was confirmed in the transformed tobacco cells with a microscope (Figure 2). We found that the green fluorescence signal of pVBG2307: CaHSP18.1a: GFP was detected in the cell membrane (Figure 2A), while the fluorescence of the empty pVBG2307: GFP vector was distributed throughout the cell (Figure 2B), indicating that CaHSP18.1a is localized to the cell membrane.

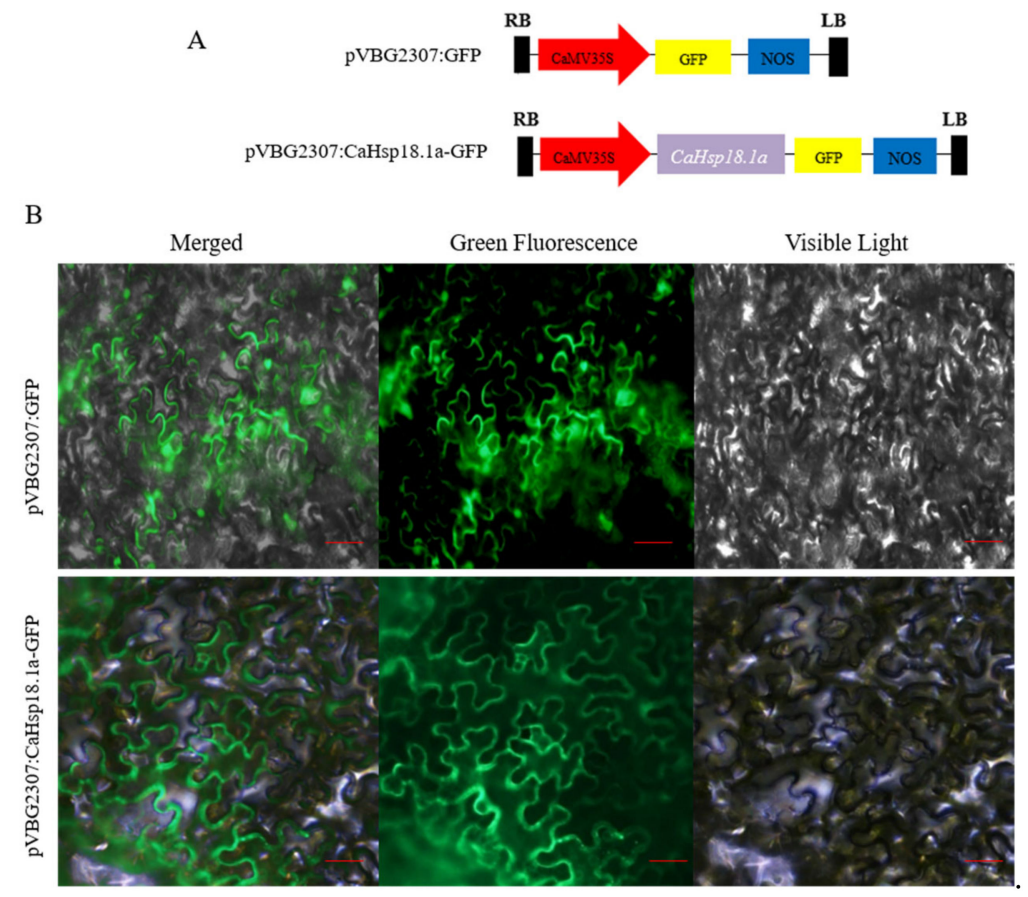

Figure 2. Transient expression of CaHSP18.1a in tobacco. (A) Schematic diagram of the CaHSP18.1a subcellular localization expression vector. (B) Subcellular localization of the CaHSP18.1a protein in tobacco leaves, with pVBG2307: GFP as control. Scale bar $=50 \mu \mathrm{m}$.

\subsection{CaHSP18.1a-Silenced Plants Sensitive to Abiotic Stress}

Confirming the VIGS procedure, after about 40-45 days, plants injected with the positive control TRV2: CaPDS showed a large area of typical white leaves (Supplementary Figure S1A), while under normal conditions there was no difference between CaHSP18.1asilenced (TRV2:CaHSP18.1a) and negative control (TRV2:00) pepper plants. The silencing efficiency of CaHSP18.1a-silenced and TRV2:00 plants was assessed using q RT-PCR. As shown in Supplementary Figure S1A, the expression level of CaHSP18.1a in the silenced pepper plants decreased to less than $20 \%$ of that observed in the negative control plants. Thus, the silencing efficiency for CaHSP18.1a-silenced plants reached more than 80\% (Supplementary Figure S1B). Therefore, control plants (TRV2:00) and silenced plants (TRV2:CaHSP18.1a) were used for the follow-up investigation.

HS $\left(42^{\circ} \mathrm{C}\right)$ was applied to CaHSP18.1a-silenced and control pepper plants for $3 \mathrm{~h}$, and the silenced plants and the control group began to show different degrees of wilting. The heat-stress treatment $\left(42^{\circ} \mathrm{C}\right)$ induced significantly different symptoms after $24 \mathrm{~h}$, such that the new growth of CaHSP18.1a-silenced plants was seriously wilted with curled leaves and shed lower leaves, while the leaves of the control plants were only slightly curled (Figure 3A). In addition, the MDA content and REL was lower in the control plants compared to CaHSP18.1a-silenced pepper plants (Figure 3B,C); however, the total chlorophyll content was higher in the control than in the CaHSP18.1a-silenced plants (Supplementary Figure S1C). 

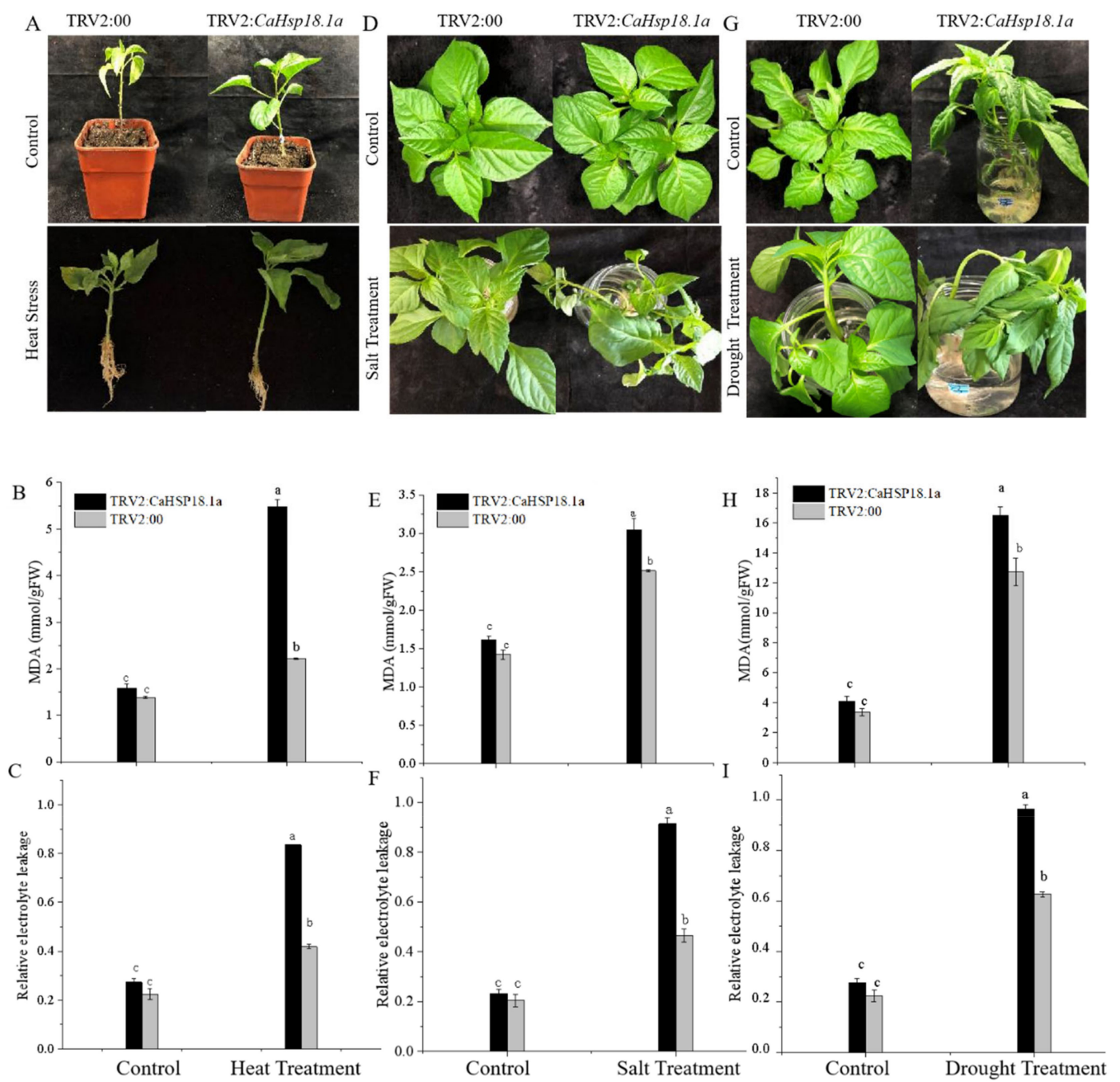

Figure 3. TRV2:CaHSP18.1 $a$ and TRV2:00 plant phenotypes under heat, drought, and salt treatments, respectively. (A-C) TRV2:CaHSP18.1 $a$ and TRV2:00 plant phenotypes, malonaldehyde (MDA) content, and relative electrolyte leakage (REL) under the $42{ }^{\circ} \mathrm{C}$ heat treatment for $24 \mathrm{~h}$; (D-F) TRV2:CaHSP18.1 $a$ and TRV2:00 plant phenotypes, MDA content, and relative electrolyte leakage (REL) following salt stress by being soaked in $300 \mathrm{mM} \mathrm{NaCl}$ solution for $24 \mathrm{~h}$; (G-I) TRV2:CaHSP18.1a and TRV2:00 plant phenotypes, MDA content, and REL following drought stress by being soaked in $300 \mathrm{mM}$ mannitol solution for $24 \mathrm{~h}$. Data are means with standard deviations of three biological replicates. Different letters denote statistical significance $(p \leq 0.05)$.

To study the salt-tolerance of silenced and control plants, we washed their roots and soaked them in $300 \mathrm{mM} \mathrm{NaCl}$ solution for $24 \mathrm{~h}$. The leaves of silenced plants showed symptoms of wilting, shriveling, and serious yellowing, with lower leaves that had begun to absciss, while the leaves of the control plants only showed some yellowing and did not exhibit obvious wilting. The leaves of the control plants showed only yellowing and no apparent wilting (Figure 3D). The MDA content of both plants increased significantly, but that of silenced plants was higher than that of control plants (Figure 3E). Relative electrolyte leakage (REL) was higher in silenced plants compared to control plants (0.96 versus 0.65) (Figure 3F). To study the effects of CaHSP18.1a-silencing on drought tolerance, the silenced and control plants were soaked in $300 \mathrm{mM}$ mannitol solution for $36 \mathrm{~h}$. The CaHSP18.1a-silenced pepper showed severe loss of water and wilting, while control plants showed no obvious change (Figure 3G). Furthermore, the MDA content and REL both exhibited a similar increase in the silenced pepper plants (Figure $3 \mathrm{H}, \mathrm{I})$. This indicated that silencing of CaHSP18.1a reduced the drought tolerance of pepper plants. 


\subsection{Effect of CaHSP18.1a Overexpression on Transgenic Arabidopsis}

\subsubsection{Overexpression of CaHSP18.1a Enhances Plant Tolerance of Heat Stress}

First, we transformed pVBG2307:CaHSP18.1a into Agrobacterium tumefaciens strain GV3101, which was used to transfect Arabidopsis thaliana using the dipping method; successful transformants were identified through resistance gene screening and molecular level detection until homozygous T3 lines were obtained (Supplementary Figure S2A). The wild-type (WT) line and five transgenic lines were cultured on Murashige and Skoog (MS) medium for 10 days, and the lengths of their roots were measured. The survival rate of WT plants was lower than those of the OE1, OE2, and OE3 seedlings (Supplementary Figure S2C,D). Transgenic plants and WT plants were cultured under normal growth conditions for 48 days, and the growth rates of the OE1, OE2, and OE3 lines exceeded those of WT plants (Supplementary Figure S2D). Thus, the OE3, OE2, and OE1 lines were selected for follow-up experiments.

The obtained transgenic lines and WT plants were heat treated $\left(42{ }^{\circ} \mathrm{C}\right.$ for $\left.24 \mathrm{~h}\right)$ at the 3-week stage. After heat-stress treatment, the WT plants showed wilting symptoms. Notably, restorable wilt or indistinct-symptoms were observed among the CaHSP18.1a-OE seedlings (Figure 4A), indicating that CaHSP18.1a plays an active role in increasing the thermotolerance of transgenic Arabidopsis. In addition, REL and MDA content increased significantly in both the OE and WT lines after heat treatment, while the MDA content was notably lower in the transgenic lines relative to the WT plants (Figure 4B). In addition, the SOD and POD activities of CaHSP18.1a-OE seedlings were clearly higher than those of the WT plants (Figure 4C,D). However, the catalase (CAT) activity did not significantly differ between the WT and transgenic lines (Figure 4E). CaHSP18.1 a played a role in transgenic Arabidopsis, probably by regulating the expression of endogenous genes.

In the present study, among 18 stress-related genes, 12 were up-regulated in transgenic lines, while the other 6 did not change much (Figure 5). Among the up-regulated genes, AtHSPC 30, AtAPX3, AtCAT, AtHSP70, and AtRab1 were more prominently expressed in the transgenic OE3 line. Moreover, the expression of the 18 stress-related genes was markedly increased in both transgenic Arabidopsis and WT plants under heat stress. However, the expression of these genes in WT seedlings was lower than that in transgenic seedlings (Figure 5). 


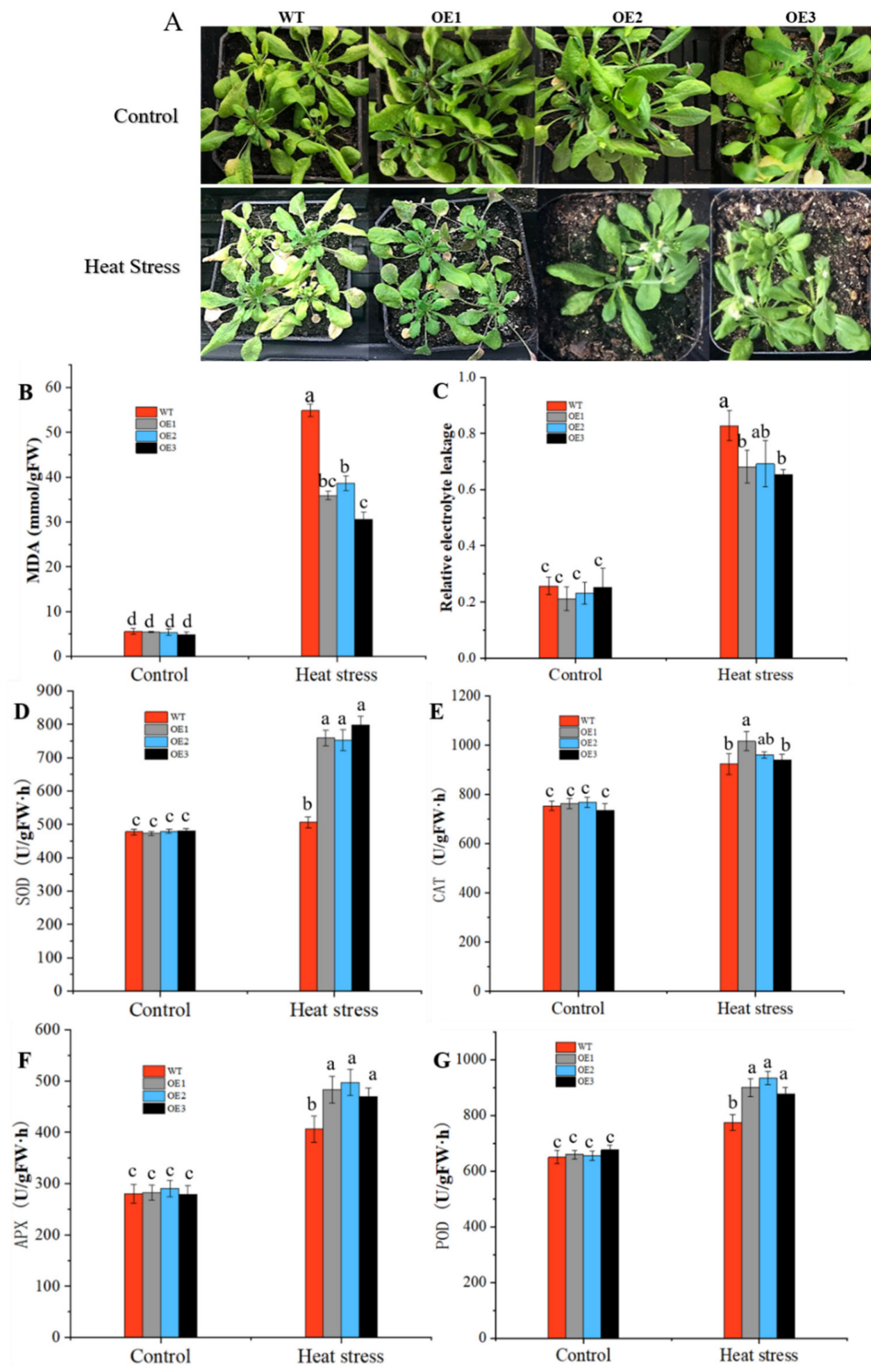

Figure 4. Heat resistance of transgenic CaHSP18.1a-OE Arabidopsis plants. (A) Phenotypes of $42{ }^{\circ} \mathrm{C}$-treated wild-type (WT) and transgenic Arabidopsis; (B-C) Malonaldehyde (MDA) and relative electrolyte leakage (REL) of WT and transgenic Arabidopsis; (D-G) Superoxide dismutase (SOD), catalase (CAT), peroxidase (POD), and ascorbic acid peroxidase (APX) activity of WT and transgenic Arabidopsis. Data are means with standard deviations of three biological replicates. Different letters denote statistical significance $(p \leq 0.05)$. 

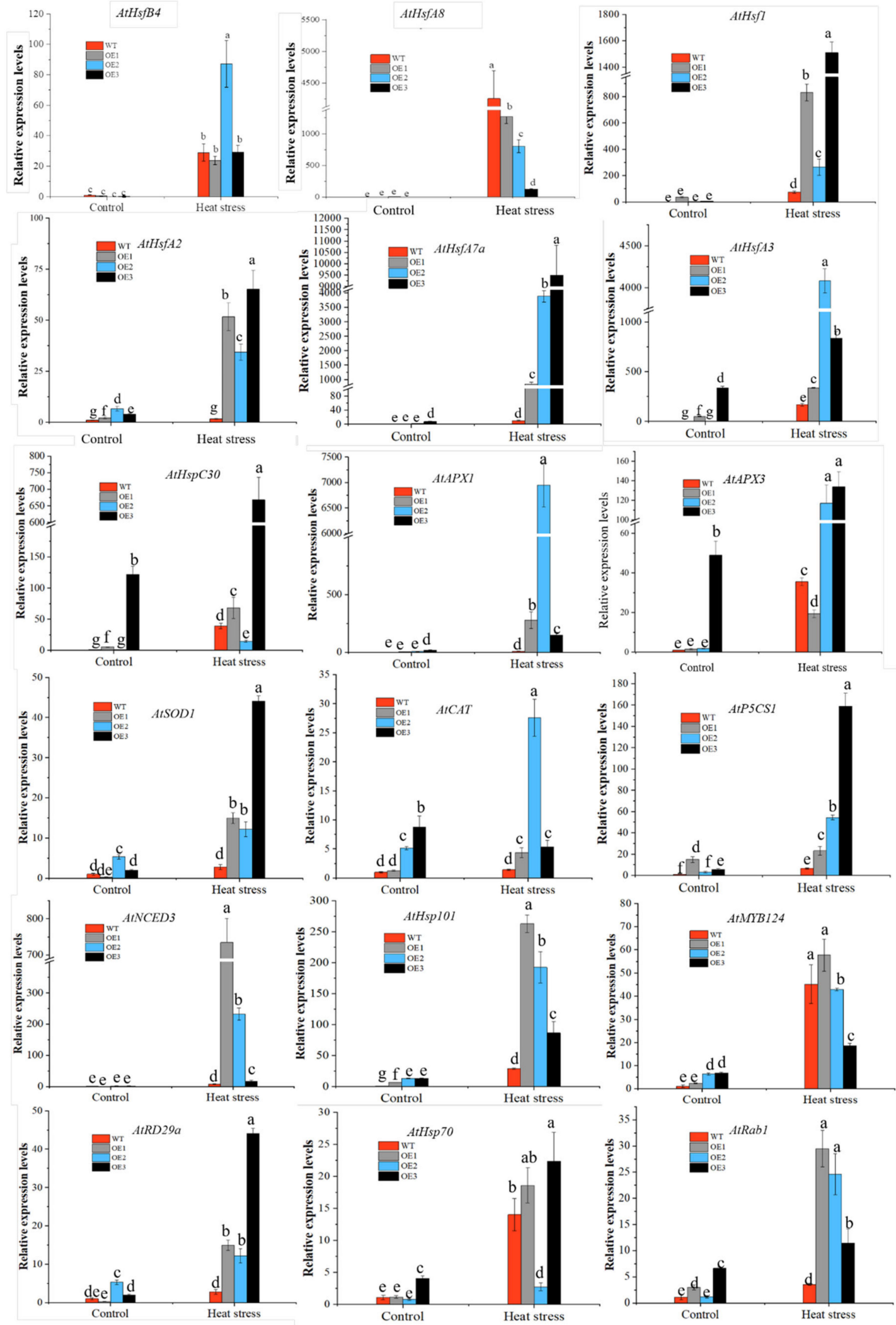

Figure 5. Expression patterns of stress-response genes in wild-type (WT), OE1, OE2, and OE3 lines before and after $42{ }^{\circ} \mathrm{C}$ heat treatment for $24 \mathrm{~h}$. Data are means with standard deviations of three biological replicates. Different letters denote statistical significance $(p \leq 0.05)$. 


\subsubsection{Overexpression of CaHSP18.1a Enhances Plant Tolerance to Drought Stress}

CaHSP18.1a is a molecular chaperone, though its response to drought stress is still unclear. To further study its function under drought and salt stress, CaHSP18.1a transgenic Arabidopsis thaliana and WT seedlings were drought treated (Figure 6A). After water control treatment was conducted for $10 \mathrm{~d}$ on 3-week-old plants with consistent growth, WT plants showed severe wilting; the leaves turned yellow, while overexpression plants grew better than WT plants (Figure 6A). These results indicated that CaHSP18.1a increases drought tolerance of transgenic Arabidopsis. In addition, the MDA content and REL were increased in both the WT and OE lines, whereas the MDA content of transgenic seedlings was obviously lower than that of WT plants (Figure 6B,C). Thus, the degree of damage in OE plants was lower than that in WT plants. The SOD, CAT, and peroxidase (POD) activity showed an upward trend in both the WT and OE lines, but the activity level of SOD, CAT, and POD in transgenic seedlings was notably higher than that in WT plants (Figure 6D,F,G). While ascorbic acid peroxidase (APX) activity increased, there was, however, no visible difference between CaHSP18.1a-OE and WT lines (Figure 6E). The expression levels of the 18 stress-related genes were induced to varying degrees by drought stress. However, the expression of AtHsfA2, AtHSPC30, and AtAPX1 exhibited almost no change in WT seedlings, and all of them were strongly increased in CaHSP18.1a-OE lines after drought stress. In addition, the expression levels of other genes were higher in transgenic lines compared to the WT plants after drought stress (Figure 7). Thus, the 18 stress-related genes examined may be involved at different levels in the response of CaHSP18.1a-OE lines to drought stress.

\subsubsection{Overexpression of CaHSP18.1a Enhances Plant Tolerance to Salt Stress}

To study the role of CaHSP18.1a in salt stress, transgenic Arabidopsis thaliana was subjected to salt stress. First, the germination rate of transgenic seeds under salt stress was observed (Supplementary Figure S3A). OE2, OE1, and WT seeds exhibited normal germination on MS plates without $\mathrm{NaCl}$; the germination rate and seedling growth of transgenic lines were almost unaffected by $100 \mathrm{mM} \mathrm{NaCl}$ MS plates. However, the seed germination rate differed when the $\mathrm{NaCl}$ concentration was increased to $150 \mathrm{mM}$, and the germination rate of WT seeds was slightly lower than that of transgenic seeds. The salt tolerance of CaHSP18.1a transgenic Arabidopsis seeds increased. After the germinated seedlings were moved to MS plates with $\mathrm{NaCl}$ concentrations of 0,100 , and $150 \mathrm{mM}$, compared with the untreated seedlings, the growth of OE2, OE3, OE1, and WT seedlings after $6 \mathrm{~d}$ under 100 and $150 \mathrm{mM} \mathrm{NaCl}$ treatments was worse (Supplementary Figure S3A,B); root elongation was significantly inhibited, and the root length of transgenic lines seedlings was greater than that of WT plants (Figure 8A). 

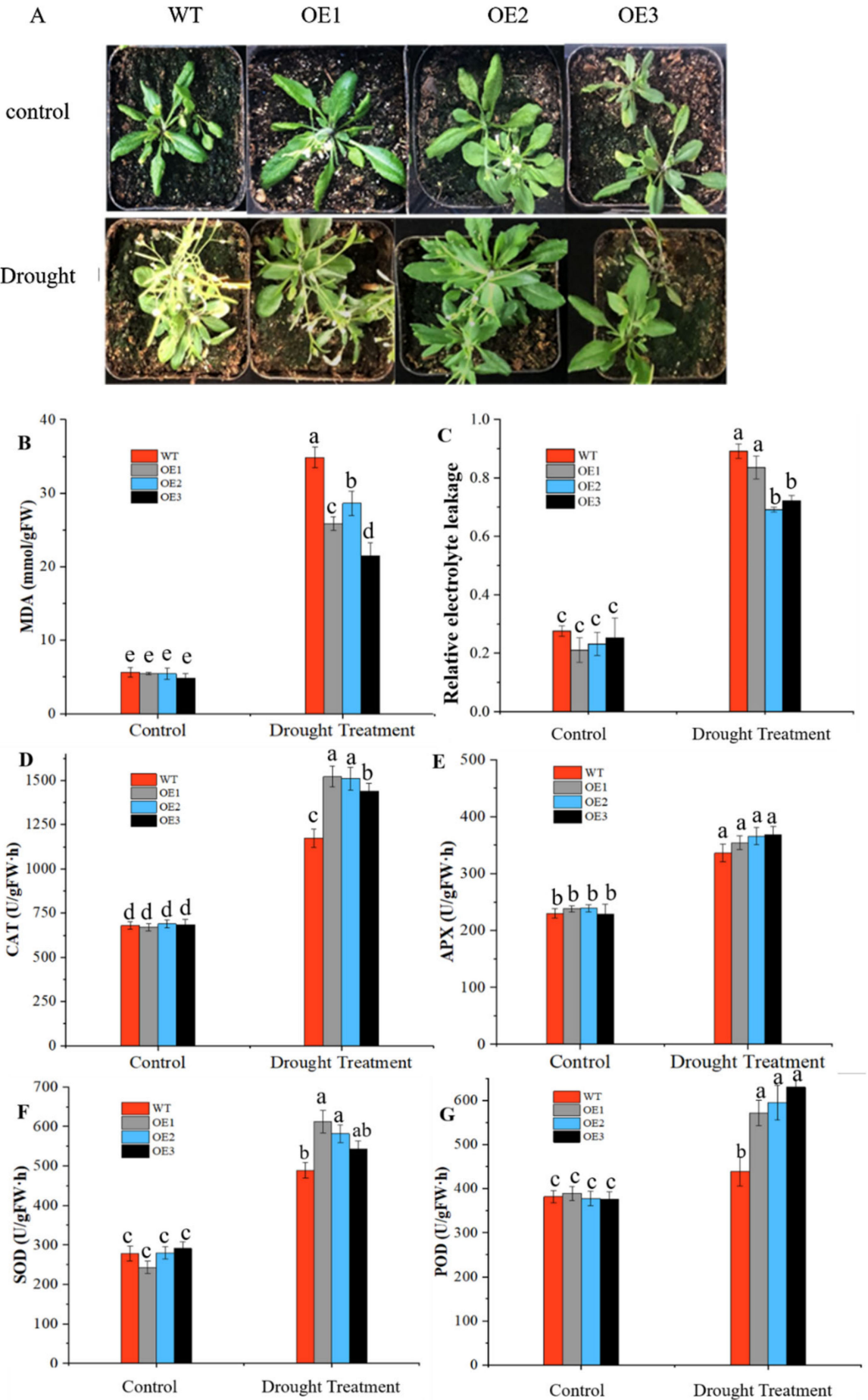

Figure 6. Drought resistance of transgenic CaHSP18.1a-OE Arabidopsis plants. (A) Phenotypes of wild-type (WT) and CaHSP18.1a-OE Arabidopsis; (B,C) Malonaldehyde (MDA) content and relative electrolyte leakage (REL) of WT and CaHSP18.1a-OE Arabidopsis; (D-G) Superoxide dismutase (SOD), catalase (CAT), peroxidase (POD), and ascorbic acid peroxidase (APX) activity of WT and CaHSP18.1a-OE Arabidopsis without watering for 10 days. Data are means with standard deviations of three biological replicates. Different letters denote statistical significance $(p \leq 0.05)$. 

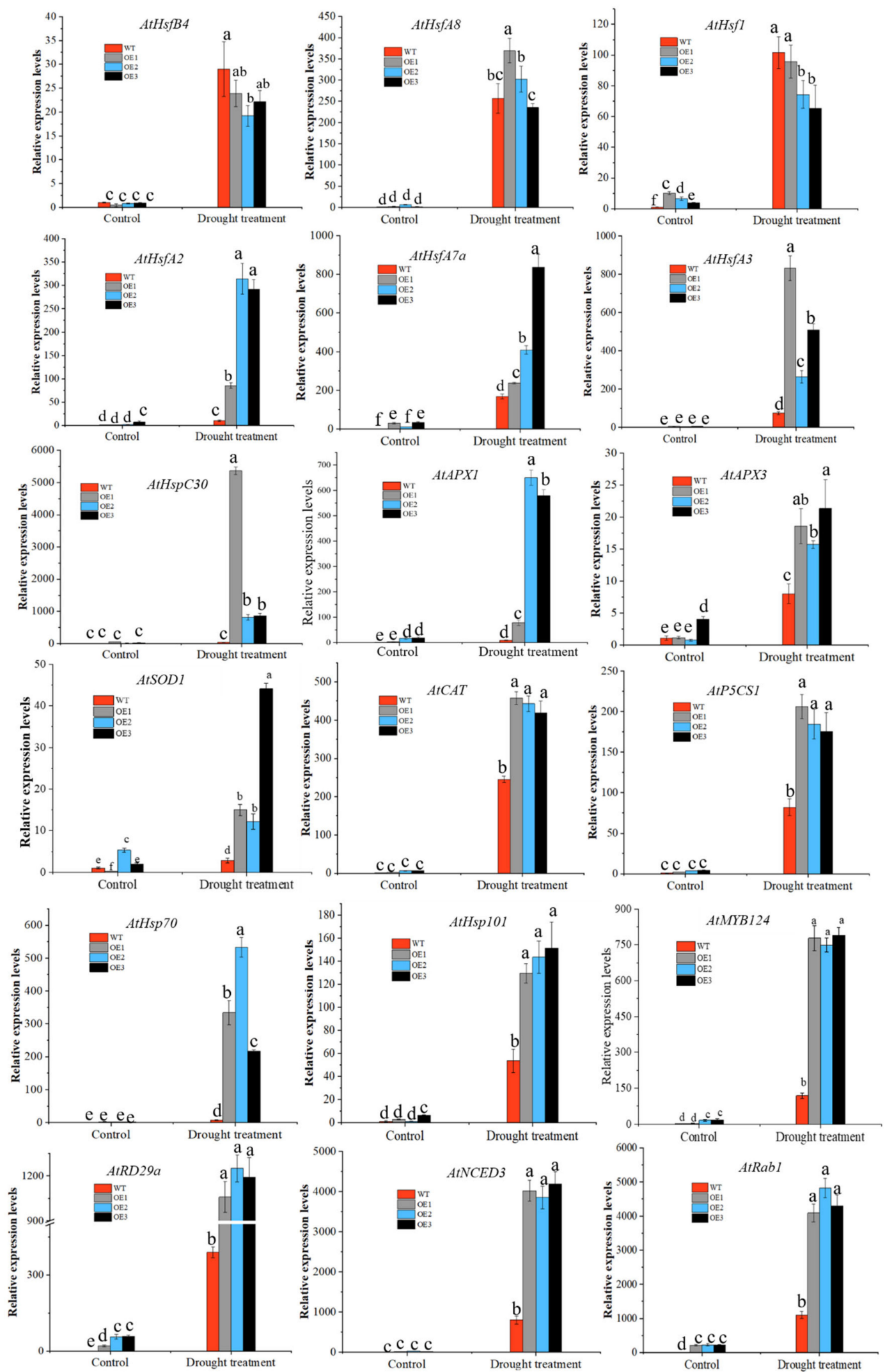

Figure 7. Expression pattern of stress-response genes in wild-type (WT), OE1, OE2, and OE3 lines before and after 10 days of drought treatment. Data are means with standard deviations of three biological replicates. Different letters denote statistical significance $(p \leq 0.05)$. 


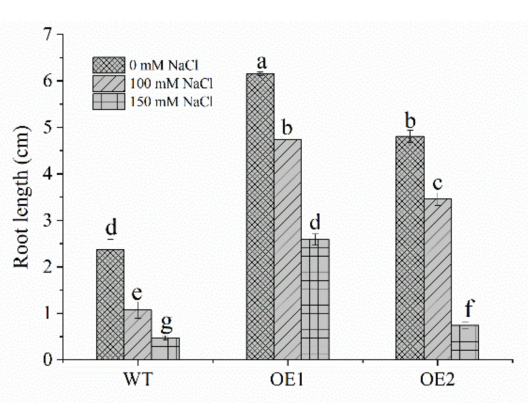

(A)

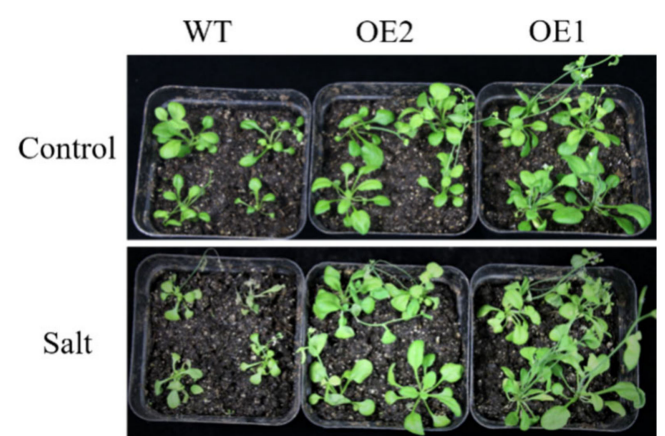

(B)

Figure 8. Overexpression of CaHSP18.1a enhanced tolerance to salt stress. (A) Root length of wild-type (WT) and CaHSP18.1a-OE Arabidopsis lines grown for $10 \mathrm{~d}$ on Murashige and Skoog (MS) medium containing 0, 100, and 150 mM $\mathrm{NaCl}$. (B) Seedling growth for WT and transgenic plants exposed to $\mathrm{NaCl}$. Three-week-old seedlings were watered with $200 \mathrm{mM} \mathrm{NaCl}$ once every 1-2 days. The images were taken after 7 days.

To explore the effect of CaHSP18.1a on the salt tolerance of Arabidopsis thaliana, 3week-old WT and transgenic plants were irrigated with $200 \mathrm{mM} \mathrm{NaCl}$ solution for 7 days. As shown in Figure 8B, WT plants showed dehydration and wilting with weak growth. However, the transgenic Arabidopsis thaliana showed no significant difference from the control plants except for a slight yellowing phenotype in their leaves.

\section{Discussion}

Plants are inevitably subjected to various extreme environmental conditions, such as heat, drought, oxidation and salt damage [36]. Under such adverse conditions, sHsP20s make a valuable protective contribution [19]. Plant HSPs are linked to heat tolerance and have been confirmed in many species [31,49]. Guo et al. [30] identified sHsP20s in pepper, and showed that CaHSP18.1a was induced in different tissues of pepper plants under heat stress, but the function of CaHSP18.1 $a$ under heat, salt, and drought stress has not been further studied. In this study, we identified that CaHSP18.1 $a$ is positively involved in plant tolerance to heat and salt, drought stress.

CaHSP18.1 $a$ was responsive to heat stress in both R9 and B6 plants and strongly induced [30]. In accordance with the results, we also found that the expression level of CaHSP18.1a was strongly induced in both the R9 and B6 lines after heat stress treatment (Figure 1B-D). However, under heat stress, the expression of CaHSP18.1a in R9 plants was higher than that in B6 plants (Figure 1B-D). This may be because R9 is a thermo-tolerant cultivar, it has better thermo-tolerance and adaptability than B6 under heat stress. The heat tolerance of plants is related to the dynamic expression patterns of heat stress-related genes [50]. Under heat stress, other HSP20s or HSPs in R9 are also strongly and rapidly induced in the early stage of heat stress $(0.5-1 \mathrm{~h})$. It had also been reported that the expression level of CaHSP25.8 and CaHSP30.1 in R9 was higher than B6, but with the extension of heat stress treatment time, the expression level of these two genes in B6 were higher than R9 [30]. However, these results also showed that the expression of CaHSP18.1a was lower at V in R9 than in B6. The expression of pepper HSP20s is regulated by many transcription factors, such as HSFs [51]. Under heat stress, it is because HSFs that regulate the expression of $\mathrm{CaHSP18.1a}$ in pepper variety $\mathrm{R} 9$ and $\mathrm{B} 6$ are different, or the expression of the same HSFs that regulate the expression of CaHSP18.1a is different in R9 and B6, causing the differential expression of CaHSP18.1 $a$ in B6 and R9 [51,52]. Therefore, the difference in the expression of CaHSP18.1a between heat-resistant and heat-sensitive varieties is due to the above reasons. However, the relationship between the function of this gene and the heat-resistance mechanism of pepper still needs further research.

In addition, CaHSP18.1 $a$ was induced under salt and drought stress (Figure 1E-H). The expression of CaHSP18.1a in R9 leaves and roots was highest under the $150 \mathrm{mM}$, $100 \mathrm{mM} \mathrm{NaCl}$ treatments, respectively (Figure 1E,F). The expression of CaHSP18.1a in R9 
leaves was the highest after the $150 \mathrm{mM}$ mannitol treatment; the highest expression of CaHSP18.1 $a$ was observed in R9 roots subjected to the $50 \mathrm{mM}$ mannitol treatment (Figure $1 \mathrm{G}, \mathrm{H})$. However, the expression of the CaHSP18.1a decreased at higher $\mathrm{NaCl}$ and mannitol concentrations. The response pattern of CaHSP18.1 $a$ that rapidly and sharply responded to salt and drought stress in a short time, and then had slight variations, was similar to quite a few HSP20s such as TaHSP23.9 [53] and ClHSP22.8 [54]. Thus, CaHSP18.1a may play a role in pepper which rapidly adapts to drought and salt stress.

VIGS technology is an important method used to study gene function under adverse environments [55]. In the R9 line, silencing of CaHSP16.4 reduces heat tolerance and drought resistance of pepper plants [31]; CaHSP22.0-silenced peppers showed more sensitivity to salt and heat stress, which was mainly reflected in decreased antioxidant enzyme activity, increased leaf conductivity, and increased superoxide anion and MDA contents [34] MDA content and REL are products of cell membrane lipid peroxidation, which damages the integrity of plasma membranes under salt or heat stress [35] and may sensitize plants to subsequent stress [56]. MDA content, total chlorophyll content, and REL are widely used to determine the degree to which plants have been damaged by abiotic stress [4]. It has also been reported that proline content, MDA content, and POD and SOD activity of pepper were significantly related to the variation in heat tolerance and temperature stress time, which can be used as an index for heat resistance identification [57].

In this study, after treatments with high temperature, salt, and drought stress, the content of MDA and REL in peppers that had been silenced for CaHSP18.1a was higher than that of the controls, indicating that the damage to cell membranes increased in CaHSP18.1a-silenced plants (Figure 3A-C). It was also found that the CaHSP18.1a-silenced plants had lower total chlorophyll content when exposed to heat stress (Figure 3B and Supplementary Figure S1C). These results demonstrated that silencing of CaHSP18.1a reduced pepper stress tolerance (Figure 3). In contrast, overexpression of CaHSP18.1a in Arabidopsis thaliana transgenic lines was associated with minimal injury symptoms, increased REL, and decreased MDA content compared with WT plants (Figures 4 and 6). These results showed that CaHSP18.1a increases plant tolerance to heat, salt, and drought stresses.

HSP20s are widely distributed in plants, and their location may be related to their function, as exemplified by AtHsP21 being localized to chloroplasts [23]. CaHSP18.1a was predicted to have cytoplasm localization [30]. Subcellular localization of CaHSP18.1a is shown in Figure 2, which confirmed that it is localized to the cell membrane.

Studies have shown that HSP20 is a molecular chaperone that can also participate in antioxidant mechanisms of plants [6,58]. HSP20scan cooperate with the plant's antioxidant scavenging system to protect plants from secondary damage $[59,60]$. For example, overexpression of AtHSP17.6 can increase CAT enzyme activity and further regulate abiotic stress responses [61]. Furthermore, the over-expression of ZmHSP16.9 in tobacco can increase the activities of POD, CAT and SOD, and enhance oxidative stress tolerance [62]. In this study, SOD, CAT, POD, and APX enzyme activities in overexpression of CaHSP18.1a plants were significantly enhanced under heat and drought stress. This is similar to the results obtained with Arabidopsis transformed with CaHSP25.9; that is, by increasing the activities of ROSscavenging related antioxidant enzymes, the heat, salt, and drought tolerance of plants can be increased [31,63]. It has been reported that plants have built defense mechanisms that scavenge excess reactive oxygen species (ROS) throughout their long evolutionary histories [64-66], such as ROS-scavenging non-enzymatic antioxidants (e.g., ascorbic acid (AsA), glutathione, and proline) [67] and antioxidant enzymes (e.g., peroxidase (POD), catalase (CAT), superoxide dismutase (SOD), and glutathione peroxidase (GPX)) that prevent secondary oxidative stress caused by abiotic stress [68-70]. Moreover, the expression levels of AtSOD1, AtAPX1, AtAPX3, and AtCAT1 were also increased by heat and drought stress, and were higher in the CaHSP18.1a transgenic Arabidopsis than in the WT. This indicated that CaHSP18.1a may improve stress resistance through the ROS-scavenging system, but the specific mechanism needs further study. 
Many stress-related genes are involved in plant responses to heat, salt, and drought stresses. It has been reported that $A t H s f A 2$ is a heat shock transcription factor that enables prolonged acquired thermo-tolerance, and it can enhance tolerance to salt and osmotic stresses [71-73]. s HSPs are downstream target genes of HsfA2 [74]. Burke [75,76] have also shown that AtHSA32 and AtHSP101 expression can be induced by high temperature and participate in the acquired thermo-tolerance of plants. AtMYB44 can be induced by salt, drought, and other stresses to participate in the abscisic acid (ABA) signaling pathway; Refs. $[77,78]$ found that the ABA signaling response gene AtDREB2A can be induced by low temperature stress. The drought responsive gene $A t R D 29 A$ was up-regulated under heat, salt, and drought stresses [79], while the molecular chaperone HSP70 participates in drought and heat stress responses [28]. NCED3 is related to biological metabolism and also participates in defense responses to drought stress [80]. Notably, HSP20s can regulate many of these stress-related genes [31,36]. For example, CaHSP16.4 and OsMSR-4 can increase the expression of these genes in transgenic seedlings, thereby enhancing stress resistance [31,81]. In this study, we assessed the expression levels of 13 stress-related genes in WT and transgenic plants. CaHSP18.1a enhanced heat tolerance in transgenic Arabidopsis, which may be closely related to its regulation of the expression of many heatstress-related genes in Arabidopsis. Overexpressed genotypes compared with wild type under normal conditions also showed higher values of stress-related genes expression, higher expression of $A t P 5 C S$, higher expression of $A t N C E D$, higher expression of $A t M Y B$, and higher expression of AtRD29, AtHsfA2, AtRab1 and AtHSP30. These results showed that $C a H S P 18.1 a$ may play an important role in regulation of these genes. Under heat stress, the expressions levels of AtHsfB4, AtHSFA8, AtHSFA2, AtHSFA7a, AtHSPC30, AtHSFA3, AtHSP70, and AtHSP101 in transgenic plants were significantly higher than WT plants (Figure 5). In particular, the AtHSPC 30 and AtHSP70 transcripts were present at levels nearly 3-fold higher in transgenic seedings than in WT plants; the transcript level of AtHsfA2 was also up-regulated in transgenic plants. The expression levels of AtHSP70, AtHSP101, AtDREB2A, AtMYB124, AtNCED3, AtRD29A, and AtRAB1 were higher (Figure 7) in the CaHSP18.1a transgenic Arabidopsis than in WT plants under drought stress. Similar results were also reported by Feng and Huang [31,32]. Thus, CaHSP18.1 $a$ may respond to heat and drought stress through its complex regulatory network.

\section{Conclusions}

In this study, we first analyzed the expression of CaHSP18.1 $a$ in R9 and B6 pepper lines and demonstrated that CaHSP18.1 $a$ was expressed when induced by abiotic stress factors such as high temperature, drought, and high salinity. CaHSP18.1a silencing decreased the resistance of pepper plants to heat, drought, and salt stresses through different molecular and physiological mechanisms. Overexpression analyses of CaHSP18.1a in transgenic Arabidopsis further confirmed that CaHSP18.1a functions positively in responses to heat, drought, and salt stresses. The expression levels of other stress-related genes were also measured, and some were determined to be significantly affected by CaHSP18.1a overexpression. We further confirmed that CaHSP18.1a protein was localized in the cell membrane. Collectively, these results show CaHSP18.1a likely acts as a positive regulator of the response to abiotic stresses in pepper.

Supplementary Materials: The following are available online at https:/ / www.mdpi.com/article/ 10.3390/horticulturae7050117/s1, Figure S1: Detection of silencing efficiency of CaHsp18.1a gene mediated by TRV2; Figure S2: Validation and acquisition of homozygous strain of T3 generation of Arabidopsis with overexpression of CaHsp18.1a; Figure S3: Germination of the transgenic Arabidopsis under salt stress; Table S1: The main primers sequence used in this research.

Author Contributions: S.L., Y.-L.L. and Z.-H.G. conceived and designed the research; S.L. and Y.-L.L. conducted the experiments and wrote the manuscript; G.-X.C. and Y.-L.L. analyzed the data; H.S.u., S.L. and J.-J.X. critically revised the manuscript; Z.-H.G. contributed reagents and funded the project. All authors have read and agreed to the published version of the manuscript. 
Funding: We highly appreciate the financial support of the funding from the National Natural Science Foundation of China (No. U1603102, No. 31772309).

Institutional Review Board Statement: Not applicable.

Informed Consent Statement: Not applicable.

Data Availability Statement: Data is contained within the article.

Conflicts of Interest: The authors declare no conflict of interest.

$\begin{array}{ll}\text { Abbreviations } \\ \text { ACD } & \text { alpha-crystallin domain } \\ \text { HS } & \text { heat stress } \\ \text { HSP } & \text { heat shock proteins } \\ \text { sHSPs } & \text { small heat shock proteins } \\ \text { REL } & \text { relative electrolyte leakage } \\ \text { MDA } & \text { Malondialdehyde } \\ \text { OE } & \text { Overexpression } \\ \text { OE1 } & \text { No. 1 Arabidopsis line with overexpressed CaHSP18.1a } \\ \text { OE2 } & \text { No. 2 Arabidopsis line with overexpressed CaHSP18.1a } \\ \text { OE3 } & \text { No. 3 Arabidopsis line with overexpressed CaHSP18.1a } \\ \text { R9 } & \text { a thermo-tolerant line } \\ \text { qRT-PCR } & \text { real-time fluorescence quantitative PCR } \\ \text { VIGS } & \text { virus-induced gene silencing } \\ \text { PDS } & \text { phytoene desaturase } \\ \text { TRV } & \text { tobacco rattle virus } \\ \text { ROS } & \text { reactive oxygen species } \\ \text { APX } & \text { ascorbate peroxidase } \\ \text { CAT } & \text { catalase } \\ \text { SOD } & \text { superoxide dismutase } \\ \text { POD } & \text { peroxidase } \\ & \end{array}$

\section{References}

1. Ahuja, I.; de Vos, R.C.H.; Bones, A.M.; Hall, R.D. Plant molecular stress responses face climate change. Trends Plant Sci. 2010, 15, 664-674. [CrossRef] [PubMed]

2. Wang, W.; Vinocur, B.; Altman, A. Plant responses to drought, salinity and extreme temperatures: Towards genetic engineering for stress tolerance. Planta 2003, 218, 1-14. [CrossRef] [PubMed]

3. McLoughlin, F.; Basha, E.; Fowler, M.E.; Kim, M.; Bordowitz, J.; Katiyar-Agarwal, S.; Vierling, E. Class I and II Small Heat Shock Proteins Together with HSP101 Protect Protein Translation Factors during Heat Stress. Plant Physiol. 2016, 172, 1221-1236. [PubMed]

4. Muthusamy, S.K.; Dalal, M.; Chinnusamy, V.; Bansal, K.C. Genome-wide identification and analysis of biotic and abiotic stress regulation of small heat shock protein (HSP20) family genes in bread wheat. J. Plant Physiol. 2017, 211, 100-113. [CrossRef] [PubMed]

5. Xiang, J.; Chen, X.; Hui, W.; Xiang, Y.; Yan, M.; Wang, J. Overexpressing heat-shock protein OsHSP50.2 improves drought tolerance in rice. Plant Cell Rep. 2018, 37, 1585-1595. [CrossRef]

6. Wang, W.; Vinocur, B.; Shoseyov, O.; Altman, A. Role of plant heat-shock proteins and molecular chaperones in the abiotic stress response. Trends Plant Sci. 2004, 9, 244-252. [CrossRef]

7. Zhang, L.; Liu, J. Research Progress of Heat Shock Protein. Guangdong Seric. 2006, 40, $39-42$.

8. Beck, E.H.; Fettig, S.; Knake, C.; Hartig, K.; Bhattarai, T. Specific and unspecific responses of plants to cold and drought stress. J. Biosci. 2007, 32, 501-510. [CrossRef]

9. Agrawal, L.; Narula, K.; Basu, S.; Shekhar, S.; Ghosh, S.; Datta, A.; Chakraborty, S. Comparative Proteomics Reveals a Role for Seed Storage Protein AmA1 in Cellular Growth, Development, and Nutrient Accumulation. J. Proteome Res. 2013, 12, 4904-4930. [CrossRef]

10. Shekhar, S.; Mishra, D.; Gayali, S.; Buragohain, A.K.; Chakraborty, S.; Chakraborty, N. Comparison of proteomic and metabolomic profiles of two contrasting ecotypes of sweetpotato (Ipomoea batata L.). J. Proteom. 2016, 143, 306-317. [CrossRef]

11. Waters, E.R.; Lee, G.J.; Vierling, E. Evolution, structure and function of the small heat shock proteins in plants. J. Exp. Bot. 1996, 47, 325-338. [CrossRef] 
12. Boston, R.S.; Viitanen, P.V.; Vierling, E. Molecular chaperones and protein folding in plants. Plant Mol. Biol. 1996, 32, 191-222. [CrossRef]

13. $\mathrm{Hu}, \mathrm{W} . ; \mathrm{Hu}, \mathrm{G}$;; Han, B. Genome-wide survey and expression profiling of heat shock proteins and heat shock factors revealed overlapped and stress specific response under abiotic stresses in rice. Plant Sci. 2009, 176, 583-590. [CrossRef]

14. Li, J.; Zhang, J.; Jia, H.; Li, Y.; Xu, X.; Wang, L.; Lu, M. The Populus trichocarpa PtHSP17.8 involved in heat and salt stress tolerances. Plant Cell Rep. 2016, 35, 1587-1599. [CrossRef]

15. Eyles, S.J.; Gierasch, L.M. Nature's molecular sponges: Small heat shock proteins grow into their chaperone roles. Proc. Natl. Acad. Sci. USA 2010, 107, 2727-2728. [CrossRef]

16. Martin, H. A first line of stress defense: Small heat shock proteins and their function in protein homeostasis. J. Mol. Biol. 2015, 427, 1537-1548.

17. Tyedmers, J.; Mogk, A.; Bukau, B. Cellular strategies for controlling protein aggregation. Nat. Rev. Mol. Cell Biol. 2010, 11, 777-788. [CrossRef]

18. Waters, E.R. The evolution, function, structure, and expression of the plant sHSPs. J. Exp. Bot. 2013, 64, 391-403. [CrossRef]

19. Lambert, W.; Koeck, P.J.B.; Ahrman, E.; Purhonen, P.; Cheng, K.; Elmlund, D.; Hebert, H.; Emanuelsson, C. Subunit arrangement in the dodecameric chloroplast small heat shock protein HSP21. Protein Sci. 2011, 20, 291-301. [CrossRef]

20. Korotaeva, N.E.; Antipina, A.I.; Grabelnykh, O.I.; Varakina, N.N.; Borovskii, G.B.; Voinikov, V.K. Mitochondrial Low-MolecularWeight Heat-Shock Proteins and the Tolerance of Cereal Mitochondria to Hyperthermia. Russ. J. Plant Physiol. 2001, 48, 798-803. [CrossRef]

21. Nieto-Sotelo, J.; Martínez, L.M.; Ponce, G.; Cassab, G.I.; Alagón, A.; Meeley, R.B.; Ribaut, J.-M.; Yang, R. Maize HSP101 Plays Important Roles in Both Induced and Basal Thermotolerance and Primary Root Growth. Plant Cell Online 2002, 14, 1621-1633. [CrossRef]

22. Sun, W.; Bernard, C.; Cotte, B.V.D.; Montagu, M.V.; Verbruggen, N. At-HSP17.6A, encoding a small heat-shock protein in Arabidopsis, can enhance osmotolerance upon overexpression. Plant J. 2010, 27, 407-415. [CrossRef]

23. Sedaghatmehr, M.; MuellerRoeber, B.; Balazadeh, S. The plastid metalloprotease FtsH6 and small heat shock protein HSP21 jointly regulate thermomemory in Arabidopsis. Nat. Commun. 2016, 7, 12439. [CrossRef]

24. Kim, D.H.; Xu, Z.; Hwang, I. AtHSP17.8 overexpression in transgenic lettuce gives rise to dehydration and salt stress resistance phenotypes through modulation of ABA-mediated signaling. Plant Cell Rep. 2013, 32, 1953-1963. [CrossRef]

25. Nicky, D.; Xu, J.; Peters, J.L.; Sunghun, P.; Ivo, R. Multi-Level Interactions Between Heat Shock Factors, Heat Shock Proteins, and the Redox System Regulate Acclimation to Heat. Front. Plant Sci. 2015, 6, 999.

26. Guo, M.; Liu, J.H.; Ma, X.; Zhai, Y.F.; Gong, Z.H.; Lu, M.H. Genome-wide analysis of the HSP70 family genes in pepper (Capsicum annuиm L.) and functional identification of CaHSP70-2 involvement in heat stress. Plant Sci. 2016, 252, 246-256. [CrossRef]

27. Zou, X. Cultivation Seasons and Cropping patterns of Capsicum in China. J. China Capsicum 2002, 3, $1672-4542$.

28. Guo, M.; Zhai, Y.-F.; Lu, J.-P.; Chai, L.; Chai, W.-G.; Gong, Z.-H.; Lu, M.-H. Characterization of CaHSP70-1, a Pepper Heat-Shock Protein Gene in Response to Heat Stress and Some Regulation Exogenous Substances in Capsicum annuum L. Int. J. Mol. Sci. 2014, 15, 19741-19759. [CrossRef]

29. Pagamas, P.; Nawata, E. Sensitive stages of fruit and seed development of chili pepper (Capsicum annuum L. var. Shishito) exposed to high-temperature stress. Sci. Hortic. 2008, 117, 21-25. [CrossRef]

30. Guo, M.; Liu, J.H.; Lu, J.P.; Zhai, Y.F.; Wang, H.; Gong, Z.H.; Wang, S.B.; Lu, M.H. Genome-wide analysis of the CaHSP20 gene family in pepper: Comprehensive sequence and expression profile analysis under heat stress. Front. Plant Sci. 2015, 6, 806. [CrossRef]

31. Huang, L.; Cheng, G.; Khan, A.; Wei, A.; Gong, Z. CaHSP16.4, a small heat shock protein gene in pepper, is involved in heat and drought tolerance. Protoplasma 2019, 256, 39-51. [CrossRef] [PubMed]

32. Feng, X.; Zhang, H.; Ali, M.; Gai, W.; Gong, Z. A small heat shock protein CaHSP25.9 positively regulates heat, salt, and drought stress tolerance in pepper (Capsicum annuum L.). Plant Physiol. Biochem. 2019, 142, 151-162. [CrossRef] [PubMed]

33. He, L.; Gao, N.; Shan, Z.; Guo, S. Pepper Chloroplast Small Heat Shock Proteins CaHSP26 Enhanced the Ability of Anti-high Temperature Stress in Arabidopsis. North. Hortic. 2011, 6, 140-143.

34. Sun, J.; Cheng, G.; Huang, L.; Liu, S.; Ali, M.; Khan, A.; Yu, Q.; Yang, S.; Luo, D.; Gong, Z. Modified expression of a heat shock protein gene, CaHSP22.0, results in high sensitivity to heat and salt stress in pepper (Capsicum annuum L.). Sci. Hortic. 2019, 249, 364-373. [CrossRef]

35. Yu, J.; Cheng, Y.; Feng, K.; Ruan, M.; Ye, Q.; Wang, R.; Li, Z.; Zhou, G.; Yao, Z.; Yang, Y.; et al. Genome-Wide Identification and Expression Profiling of Tomato HSP20 Gene Family in Response to Biotic and Abiotic Stresses. Front. Plant Sci. 2016, 7, 1215. [CrossRef]

36. Wang, M.; Zou, Z.; Li, Q.; Sun, K.; Chen, X.; Li, X. The CsHSP17.2 molecular chaperone is essential for thermotolerance in Camellia sinensis. Sci. Rep. 2017, 7, 1237. [CrossRef]

37. Zhai, Y.; Wang, H.; Liang, M.; Lu, M. Both silencing- and over-expression of pepper CaATG8c gene compromise plant tolerance to heat and salt stress. Environ. Exp. Bot. 2017, 141, 10-18. [CrossRef]

38. Wang, J.E.; Liu, K.K.; Li, D.W.; Zhang, Y.L.; Zhao, Q.; He, Y.M.; Gong, Z.H. A novel peroxidase CaPOD gene of pepper is involved in defense responses to Phytophthora capsicum infection as well as abiotic stress toleranc. Int. J. Mol. Sci. 2013, 14, 3158-3177. [CrossRef] 
39. Wan, H.; Yuan, W.; Ruan, M.; Ye, Q.; Wang, R.; Li, Z.; Zhou, G.; Yao, Z.; Zhao, J.; Liu, S.; et al. Identification of reference genes for reverse transcription quantitative real-time PCR normalization in pepper (Capsicum annuum L.). Biochem. Biophys. Res. Commun. 2011, 416, 24-30. [CrossRef]

40. Livaka, K.J.; Schmittgen, T.D. Analysis of relative gene expression data using real-time quantitative PCR and the $2^{-\Delta \Delta C_{T}}$ Method. J. Methods 2001, 25, 402-408. [CrossRef]

41. Yu, C.; Zhan, Y.; Feng, X.; Huang, Z.A.; Sun, C. Identification and Expression Profiling of the Auxin Response Factors in Capsicum annuиm L. under Abiotic Stress and Hormone Treatments. Int. J. Mol. Sci. 2017, 18, 2719. [CrossRef]

42. Clough, S.J.; Bent, A. Floral dip: A simplified method for Agrobacterium -mediated transformation of Arabidopsis thaliana. Plant J. 1998, 16, 735-743. [CrossRef] [PubMed]

43. Yin, Y.X.; Guo, W.L.; Zhang, Y.L.; Ji, J.J.; Xiao, H.J.; Yan, F.; Zhao, Y.Y.; Zhu, W.C.; Chen, R.G.; Chai, W.G. Cloning and characterisation of a pepper aquaporin, CaAQP, which reduces chilling stress in transgenic tobacco plants. Plant Cell Tissue Organ Cult. 2014, 118, 431-444. [CrossRef]

44. Arkus, K.A.J.; Cahoon, E.B.; Jez, J.M. Mechanistic analysis of wheat chlorophyllase. Arch. Biochem. Biophys. 2005, 438, 146-155. [CrossRef]

45. Campos, P.S.; nia Quartin, V.; chicho Ramalho, J.; Nunes, M.A. Electrolyte leakage and lipid degradation account for cold sensitivity in leaves ofCoffea sp. plants. J. Plant Physiol. 2003, 160, 283-292. [CrossRef] [PubMed]

46. Guo, W.L.; Chen, R.G.; Gong, Z.H.; Yin, Y.X.; Ahmed, S.S.; He, Y.M. Exogenous abscisic acid increases antioxidant enzymes and related gene expression in pepper (Capsicum annuum) leaves subjected to chilling stress. Genet. Mol. Res. GMR 2012, 11, 4063-4080. [CrossRef] [PubMed]

47. Nakano, Y.; Asada, K. Hydrogen Peroxide is Scavenged by Ascorbate-specific Peroxidase in Spinach Chloroplasts. Plant Cell Physiol. 1981, 22, 867-880.

48. Aebi, H. [13] Catalase in vitro. Methods Enzymol. 1984, 105, 121-126.

49. Jiang, C.; Xu, J.; Zhang, H.A.; Zhang, X.; Shi, J.; Li, M.I.; Ming, F. A cytosolic class I small heat shock protein, RcHSP17.8, of Rosa chinensis confers resistance to a variety of stresses to Escherichia coli, yeast and Arabidopsis thaliana. Plant Cell Environ. 2009, 32, 1046-1059. [CrossRef]

50. Lopes-Caitar, V.S.; de Carvalho, M.C.; Darben, L.M.; Kuwahara, M.K.; Nepomuceno, A.L.; Dias, W.P.; Abdelnoor, R.V.; MarcelinoGuimarães, F.C. Genome-wide analysis of the HSP20 gene family in soybean: Comprehensive sequence, genomic organization and expression profile analysis under abiotic and biotic stresses. BMC Genom. 2013, 14, 1471-2164. [CrossRef]

51. Wang, X.; Huang, W.; Yang, Z.; Liu, J.; Huang, B. Transcriptional regulation of heat shock proteins and ascorbate peroxidase by CtHsfA2b from African bermudagrass conferring heat tolerance in Arabidopsis. Sci. Rep. 2016, 6, 28021. [CrossRef]

52. Schramm, F.; Ganguli, A.; Kiehlmann, E.; Englich, G.; Walch, D.; von Koskull-Döring, P. The Heat Stress Transcription Factor HsfA2 Serves as a Regulatory Amplifier of a Subset of Genes in the Heat Stress Response in Arabidopsis. Plant Mol. Biol. 2006, 60, 759-772. [CrossRef] [PubMed]

53. Wang, J.; Gao, X.; Dong, J.; Tian, X.; Wang, J.; Palta, J.A.; Xu, S.; Fang, Y.; Wang, Z. Over-Expression of the Heat-Responsive Wheat Gene TaHSP23.9 in Transgenic Arabidopsis Conferred Tolerance to Heat and Salt Stress. Front Plant Sci. 2020, 11, 243. [CrossRef]

54. He, Y.; Yao, Y.; Li, L.; Li, Y.; Gao, J.; Fan, M. A heat-shock 20 protein isolated from watermelon (ClHSP22.8) negatively regulates the response of Arabidopsis to salt stress via multiple signaling pathways. Peer]. 2021, 9, e10524. [CrossRef] [PubMed]

55. Yao, B.; Yue, S.; Sun, L.; Ma, Z.; Su, J.; Liu, X. Development of Virus Induced Gene Silencing and Application of VIGS in Plant Abiotic Stresses. Chin. Agric. Sci. Bull. 2016, 32, 131-136.

56. Ammar, J.B.; Lanoiselle, J.-L.; Lebovka, N.I.; Hecke, E.V.; Vorobiev, E.J.J. Impact of a Pulsed Electric Field on Damage of Plant Tissues: Effects of Cell Size and Tissue Electrical Conductivity. J. Food Sci. 2011, 76, E90-E97. [CrossRef]

57. Ma, B.; Lu, M.; Gong, Z.H. Responses of growth and physiology of pepper (Capsicum annuum L.) seedlings to high temperature stress. J. Northwest A F Univ. 2013, 41, 112-118.

58. Shang, H.; Cao, S.; Yang, Z.; Cai, Y.; Zheng, Y. Effect of Exogenous $\gamma$-Aminobutyric Acid Treatment on Proline Accumulation and Chilling Injury in Peach Fruit after Long-Term Cold Storage. J. Agric. Food Chem. 2011, 59, 1264-1268. [CrossRef]

59. Rossel, J.B.; Wilson, I.W.; Pogson, B.J. Global Changes in Gene Expression in Response to High Light in Arabidopsis. Plant Physiol. 2002, 130, 1109-1120. [CrossRef] [PubMed]

60. Aghdam, M.S.; Sevillano, L.; Flores, F.B.; Bodbodak, S. Heat shock proteins as biochemical markers for postharvest chilling stress in fruits and vegetables. Sci. Hortic. 2013, 160, 54-64. [CrossRef]

61. Li, G.; Li, J.; Hao, R.; Guo, Y. Activation of catalase activity by a peroxisome-localized small heat shock protein HSP17.6CII. J. Genet. Genom. 2017, 44, 395-404. [CrossRef] [PubMed]

62. Sun, L.; Liu, Y.; Kong, X.; Zhang, D.; Pan, J.; Zhou, Y.; Wang, L.; Li, D.; Yang, X. ZmHSP16.9, a cytosolic class I small heat shock protein in maize (Zea mays), confers heat tolerance in transgenic tobacco. Plant Cell Rep. 2012, 31, 1473-1484. [CrossRef] [PubMed]

63. Meifang, L.; Xiujian, W.; Shangjing, G. Obtain of Transgenic Sweet Pepper Plants with Gene from Endoplasmic Reticulum Small Heat Shock Protein CaHSP22.5. Mol. Plant Breed. 2018, 7, 2212-2218.

64. Zhao, J.; Liang, J.; Wu, X.; Liu, X.; Li, H.; Zhu, S. Expression Profiling of Rice ROS Scavenging System Related Genes under Salt or Low Temperature Stress. Acta Bot. Boreali-Occident. Sin. 2015, 35, 872-883. 
65. Kim, J.M.; Woo, D.H.; Kim, S.H.; Lee, S.Y.; Park, H.Y.; Seok, H.Y.; Chung, W.S.; Moon, Y.H. Arabidopsis MKKK20 is involved in osmotic stress response via regulation of MPK6 activity. Plant Cell Rep. 2012, 31, 217-224. [CrossRef]

66. Tuteja, N.; Banu, M.S.A.; Huda, K.M.K.; Gill, S.S.; Jain, P.; Xuan, H.P.; Tuteja, R. Pea p68, a DEAD-Box Helicase, Provides Salinity Stress Tolerance in Transgenic Tobacco by Reducing Oxidative Stress and Improving Photosynthesis Machinery. PLoS ONE 2014, 9, e98287. [CrossRef]

67. Ron, M.; Sandy, V.; Martin, G.; Frank, V.B. Reactive oxygen gene network of plants. Trends Plant Sci. 2004, 9, 490-498.

68. Cao, S.; Yang, Z.; Cai, Y.; Zheng, Y. Fatty acid composition and antioxidant system in relation to susceptibility of loquat fruit to chilling injury. Food Chem. 2011, 127, 1777-1783. [CrossRef]

69. Foyer, C.H.; Noctor, G. Redox homeostasis and antioxidant signaling: A metabolic interface between stress perception and physiological responses. Plant Cell Online 2005, 17, 1866-1875. [CrossRef]

70. Moller, I.M. Plant Mitochondria and Oxidative Stress: Electron Transport, Nadph Turnover, and Metabolism of Reactive Oxygen Species. Annu. Rev. Plant Physiol. Plant Mol. Biol. 2001, 52, 561-591. [CrossRef]

71. Charng, Y.; Liu, H.; Liu, N.; Chi, W.; Wang, C.; Chang, S.; Wang, T. A Heat-Inducible Transcription Factor, HsfA2, Is Required for Extension of Acquired Thermotolerance in Arabidopsis. Plant Physiol. 2007, 143, 251-262. [CrossRef] [PubMed]

72. Heerklotz, D.; Döring, P.; Bonzelius, F.; Winkelhaus, S.; Nover, L. The balance of nuclear import and export determines the intracellular distribution and function of tomato heat stress transcription factor HsfA2. Mol. Cell. Biol. 2001, 21, 1759-1768. [CrossRef] [PubMed]

73. Ogawa, D.; Kazuo, Y.; Nishiuchi, T. High-level overexpression of the Arabidopsis HsfA2 gene confers not only increased themotolerance but also salt/osmotic stress tolerance and enhanced callus growth. J. Exp. Bot. 2007, 58, 3373-3383. [CrossRef] [PubMed]

74. Pv, K.D.; Scharf, K.D.; Nover, L. The diversity of plant heat stress transcription factors. Trends Plant Sci. 2007, 12, $452-457$.

75. Burke, J.J.; Chen, J. Enhancement of reproductive heat tolerance in plants. PLoS ONE 2015, 10, e0122933. [CrossRef]

76. Charng, Y.Y.; Liu, H.C.; Liu, N.Y.; Hsu, F.C.; Ko, S.S. Arabidopsis Hsa32, a novel heat shock protein, is essential for acquired thermotolerance during long recovery after acclimation. Plant Physiol. 2006, 4, 1297-1305. [CrossRef]

77. Nguyen, N.H.; Nguyen, C.T.T.; Jung, C.; Cheong, J.-J. AtMYB44 suppresses transcription of the late embryogenesis abundant protein gene AtLEA4-5. Biochem. Biophys. Res. Commun. 2019, 511, 931-934. [CrossRef]

78. Nakashima, K.; Shinwari, Z.K.; Sakuma, Y.; Seki, M.; Miura, S.; Shinozaki, K.; Yamaguchi-Shinozaki, K. Organization and expression of two Arabidopsis DREB2 genes encoding DRE-binding proteins involved in dehydration- and high-salinityresponsive gene expression. Plant. Mol. Biol. 2000, 42, 657-665. [CrossRef]

79. Verbruggen, N.; Hermans, C. Proline accumulation in plants: A review. Amino Acids 2008, 35, 753-759. [CrossRef]

80. Rymaszewski, W.; Vile, D.; Bediee, A.; Dauzat, M.; Luchaire, N.; Kamrowska, D.; Granier, C.; Hennig, J. Stress-Related Gene Expression Reflects Morphophysiological Responses to Water Deficit. Plant. Physiol. 2017, 174, 1913-1930. [CrossRef]

81. Yin, X.; Huang, L.; Zhang, X.; Wang, M.; Xu, G.; Xia, X. Expression of rice geneOsMSR4confers decreased ABA sensitivity and improved drought tolerance inArabidopsis thaliana. Plant. Growth Regul. 2015, 75, 549-556. [CrossRef] 